\title{
Using seasonal measurements to inform ecophysiology: extracting cardinal growth temperatures for process-based growth models of five Eucalyptus species/crosses from simple field trials
}

Michael S Watt ${ }^{1 *}$, Rafael Rubilar ${ }^{2}$, Mark O Kimberley ${ }^{3}$, Darren J Kriticos ${ }^{4}$, Veronica Emhart ${ }^{5}$, Oscar Mardones ${ }^{5}$, Manuel Acevedo ${ }^{2,8}$, Matias Pincheira ${ }^{2,8}$, Jose Stape ${ }^{6}$ and Tom Fox ${ }^{7}$

\begin{abstract}
Background: Development of a relatively simple growth modelling approach for plantation species that allows derivation of cardinal (base, optimum and ceiling) air temperatures for growth, whilst accounting for changes in organism size, would represent a considerable advance over existing models. Such an approach would provide insight into species phenology and, in an agronomic setting, allow growers to closely match species to sites. Here, a model is described that can be used to predict seasonal variation in growth and cardinal air temperatures from simple seasonal measurements at a single site.

Methods: The model was applied to data from an irrigated trial comprising two Eucalyptus species and three Eucalyptus crosses. Using measurements of mean daily air temperature data and stem volume, taken over a two year period, the model was fitted to the data and used to estimate cardinal air temperatures for the five species/crosses.

Results: The model predictions corresponded well to the actual data for all five species/crosses, with $R^{2}$ ranging from 0.993 to 0.999 . The optimum air temperature, $T_{0}$, for $E$. camaldulensis $\times$ E. globulus of $26.9^{\circ} \mathrm{C}$ significantly exceeded $T_{0}$ for the other four species/crosses, where $T_{0}$ ranged from 15.4 to $18.7^{\circ} \mathrm{C}$. As $T_{0}$ for $E$. camaldulensis $\mathrm{X}$ E. globulus was close to the highest mean daily air temperature recorded at the study site, the air temperature modifier for this species was almost always sub-optimal and consequently this cross was not well matched to the site. In contrast, $T_{0}$ for the other four species/crosses were considerably closer to the mean air temperature of the site with $T_{0}$ for $E$. nitens most closely approximating the mean air temperature (15.4 vs. $13.0^{\circ} \mathrm{C}$ ).
\end{abstract}

Conclusion: The described approach can be used to account for complex variation in seasonal growth patterns and provides insight into how well a species may be matched to a particular site. As climatic information is available at a range of scales (from local to global), this type of model is likely to be useful for producing maps that describe species growth and areas of optimal suitability.

Keywords: Air temperature; Eucalyptus; Hybrid model

\footnotetext{
* Correspondence: michael.watt@scionresearch.com

${ }^{1}$ Scion, PO Box 29237, Fendalton, Christchurch, New Zealand

Full list of author information is available at the end of the article
} 


\section{Background}

Process-based ecological models are applied in a wide variety of fields from agriculture to zoogeography. They are used in simulations at a range of scales from an individual organ to populations. The main attraction of these models is that they can be used to capture the general behaviour of the entity being simulated in relation to environmental covariates. This allows them to be applied to novel situations with greater confidence than simpler, purely empirical statistical models (Wang et al. 2013; Perez-Cruzado et al. 2011). This generality is useful for applications involving novel environments that might occur under biological invasions and climate change. The generality of process-based models, however, comes at a cost of greater complexity, and potentially reduced precision (Levins 1966; Sharpe 1990). This added complexity poses significant methodological challenges. The researcher has to find ways to characterise the response of the organism to significant environmental variables (most notably temperature and moisture) at a temporal scale that is relevant to the system being simulated and the questions being addressed.

Many entomologists, agronomists and pathologists have chosen to study short-lived organisms whose growth responses to air temperature are easy to characterise through simple temperature series experiments. The duration of the developmental period required to transition between two selected lifestages (e.g. seed to germinant, egg to pupa) across a range of temperatures can indicate the growth rate as a function of temperature. A simple examination of the response rate as a function of time can result in the extraction of the minimum, maximum and optimum temperatures for development (Dumar et al. 1990; Togashi 1931; Pradhan 1946; Wang et al. 2013).

Process-based models of individual and population growth for tree species are typically more complex to develop. Process-based plant growth models are often used to simulate and integrate complex processes such as carbon assimilation and partitioning, respiration and phenology (Battaglia et al. 2004; Kirschbaum 1999) so considerable complexity and a large number of parameters are often incorporated into them. Frequently, models contain parameters that are difficult to estimate or fit. As a consequence, these models often require extensive calibration to empirical growth measurements to ensure that results lie within realistic bounds (Kirschbaum and Watt 2011). Despite this complexity, process-based based models have been successfully fitted to several tree species using calibrated parameter values (Wang et al. 2013; Campoe et al. 2013; Perez-Cruzado et al. 2011; Rodriguez et al. 2009; Almeida et al. 2004a).

Plant growth models have recently been developed that combine elements of both process-based and empirical models. Such hybrid models incorporate increased biological realism over traditional empirical growth models, yet they reduce the number of parameters to be fitted. In developing a hybrid model, it is important to incorporate the key process-based elements that have most influence on growth. Air temperature and soil moisture are widely recognised as being two key factors that regulate plant growth at both seasonal and annual timescales (Sampson et al. 2006; Bollmann et al. 1986; Jones et al. 1991; Battaglia et al. 1996; Duchesne and Houle 2011; Wang et al. 2013).

Most hybrid modelling has been undertaken using annual timesteps. Typically these hybrid models modify the trajectory of empirical growth curves through incorporation of modifiers for environmental factors that have been averaged at an annual level. Substantial gains in predictive precision over purely empirical models have been reported through use of these models for a diverse range of plant species (Tian et al. 2012; Sampson et al. 2006; Waterworth et al. 2007; Mason et al. 2011; Miehle et al. 2009; Battaglia et al. 1999; Reed et al. 2003; Perez-Cruzado et al. 2011; Wang et al. 2013).

Development of a sub-annual timestep hybrid model that can be fitted to readily obtainable seasonal plant measurements and that is sensitive to both plant size and key environmental factors would represent a considerable advance over existing models. This type of model can be applied to novel climate situations, and could be used to estimate growth at time scales as fine as the available meteorological data. Such models could also be used for exploring the impacts of pests and diseases more usefully than current models by accurately simulating seasonal growth patterns. Using such a model to infer responses to air temperature and soil water balance would allow cardinal values to be determined, which would provide a useful approach for matching species or genotypes to sites (Almeida et al. 2004b; Esprey et al. 2004; Battaglia and Sands 1997) and for scheduling management operations (e.g. fertilisation, weed control) for crop species (Mason and Dzierzon 2006; Pinkard and Battaglia 2001). This type of information is also useful for parameterising more detailed process-based models that can be used to simulate changes in productivity under climate change scenarios (Medlyn et al. 2011; Kirschbaum et al. 2012).

This paper describes an inverse or inferential modelling method for deriving cardinal air temperatures from seasonal growth measurements obtained from a simple field trial. Specific objectives were to (i) develop a hybrid model that can be fitted to periodic growth measurements and (ii) use this model to estimate cardinal air temperatures. Data were obtained from an irrigated trial of five different Eucalyptus species/crosses to illustrate the utility of the model. 


\section{Methods}

\section{Description of the model}

The model uses an empirically derived form to describe growth under optimal environmental conditions. Growth is reduced from this optimal rate by a modifier that includes the discounting impacts of various sub-optimal environmental conditions. Required inputs for the model include the growth measurement of interest (e.g. height, diameter, volume) and data describing the growthconstraining environmental variables. The model may be run at any timestep over which unique sequential environmental data are available. A daily timestep is likely to be most appropriate for determination of cardinal values for key environmental variables such as air temperature. The model is fitted to the growth measurements and this data can be of a far coarser temporal resolution than the environmental data.

Growth under optimal environmental conditions (e.g. air temperature, root-zone water storage) is described by either a power or sigmoidal function (see Kimberley and Richardson, 2004 for a range of functional forms). The model fitted to the trial data described here is based on the following power function,

$$
y_{t}=a t^{b}
$$

where $y_{t}$ is the response, $t$ is time after commencement of measurement, and $a$ and $b$ are empirically derived parameters.

Assuming that the effect of environmental conditions is constant over the interval $t$ to $t+\Delta t$, growth can be expressed as a difference equation (Kimberley and Richardson 2004),

$$
y_{t+\Delta t}=y_{t}+\left[f\left(f^{-1}\left(y_{t}\right)+\Delta t\right)-y_{t}\right] m
$$

where $m$ is a modifier describing the impacts of environmental conditions on growth and $f^{-1}\left(y_{\mathrm{t}}\right)$ is the inverse of Equation 1, i.e.,

$$
f^{-1}\left(y_{t}\right)=\left(\frac{y_{t}}{a}\right)^{1 / b}
$$

Combining Equations 2 and 3 the full difference equation is,

$$
y_{t+\Delta t}=y_{t}+\left[a\left(\left(\frac{y_{t}}{a}\right)^{\frac{1}{b}}+\Delta t\right)^{b}-y_{t}\right] m
$$

This method can be extended to empirical functional forms other than the 2-parameter power function, including 3-parameter sigmoidal growth functions (Kimberley and Richardson 2004).

The modifier $m$, which scales between 0 and 1 , reduces growth when environmental conditions such as air temperature and root-zone water balance are sub- optimal. The data used here were from a well-watered trial so this modifier was only required to account for air temperature. However, under conditions where soil root-zone water storage is sub-optimal, a water-balance modifier could also be incorporated into the model.

The following modifier $(m)$ developed by Yin et al., (1995) based on the beta distribution, was used to describe the response of plant growth to air temperature, $T$,

$$
m=\left[\left(\frac{T-T_{b}}{T_{o}-T_{b}}\right)\left(\frac{T_{c}-T}{T_{c}-T_{o}}\right)^{\frac{T_{c}-T_{o}}{T_{o}-T_{b}}}\right]^{c}
$$

The modifier is defined for $T_{b} \leq T \leq T_{c}$, where $T_{b}$ is the base or minimum, $T_{c}$ the ceiling or maximum air temperature, and $T_{o}$ the optimum air temperature. Outside this temperature range, $m=0$. The response has a maximum value of 1 at $T_{o}$, and declines to 0 at both $T_{b}$ and $T_{c}$. The parameter $c$ controls the shape of the response to temperature with the weight in the tails declining with increasing values of $c$. For a symmetric response (where $T_{o}$ is midway between $T_{b}$ and $T_{c}$ ), the response approaches the shape of a normal distribution for values of $c$ greater than 10. The modifier described in Equation 5 is quite flexible in that it can be used to describe either asymmetric or symmetric temperature responses.

\section{Data used for the model \\ Study area}

Data used to fit the model was obtained from a trial established approximately $45 \mathrm{~km}$ south of Los Angeles in the Bio-Bio region of Chile (latitude $37^{\circ} 45^{\prime} \mathrm{S}$ longitude $72^{\circ} 18^{\prime} \mathrm{W}$, elevation $204 \mathrm{~m}$ a.s.l., Figure 1$)$. Soil at the site is classified as part of the Collipulli soil series Typic Rhodoxeralfs (Besoain 1985). Such soil is developed from old volcanic ashes that have formed deep highly weathered red clay soils on slightly undulated terrain in the central valley of Chile (Besoain 1985).

The area was previously occupied by an Eucalyptus spp. seed orchard and measurements at the site, prior to the trial installation, showed high levels of soil fertility and water holding capacity (Table 1 ). The climate of the area is warm and temperate. Mean annual rainfall is $1,200 \mathrm{~mm}$ with most of the precipitation occurring during winter. Mean annual temperature is $13.1^{\circ} \mathrm{C}$ with a maximum summer mean of $18^{\circ} \mathrm{C}$ and a minimum winter mean of $6^{\circ} \mathrm{C}$.

\section{Trial design and treatments}

An irrigated and completely randomised block design was established in mid-spring (28 October) 2008 with three replicates of two Eucalyptus species (Eucalyptus globulus Labill. and E. nitens H. Deane \& Maiden) and three Eucalyptus crosses (E. camalulensis Dehnh $\mathrm{x} E$. globulus, E. nitens x E. camaldulensis and E. nitens $\mathrm{x} E$. 


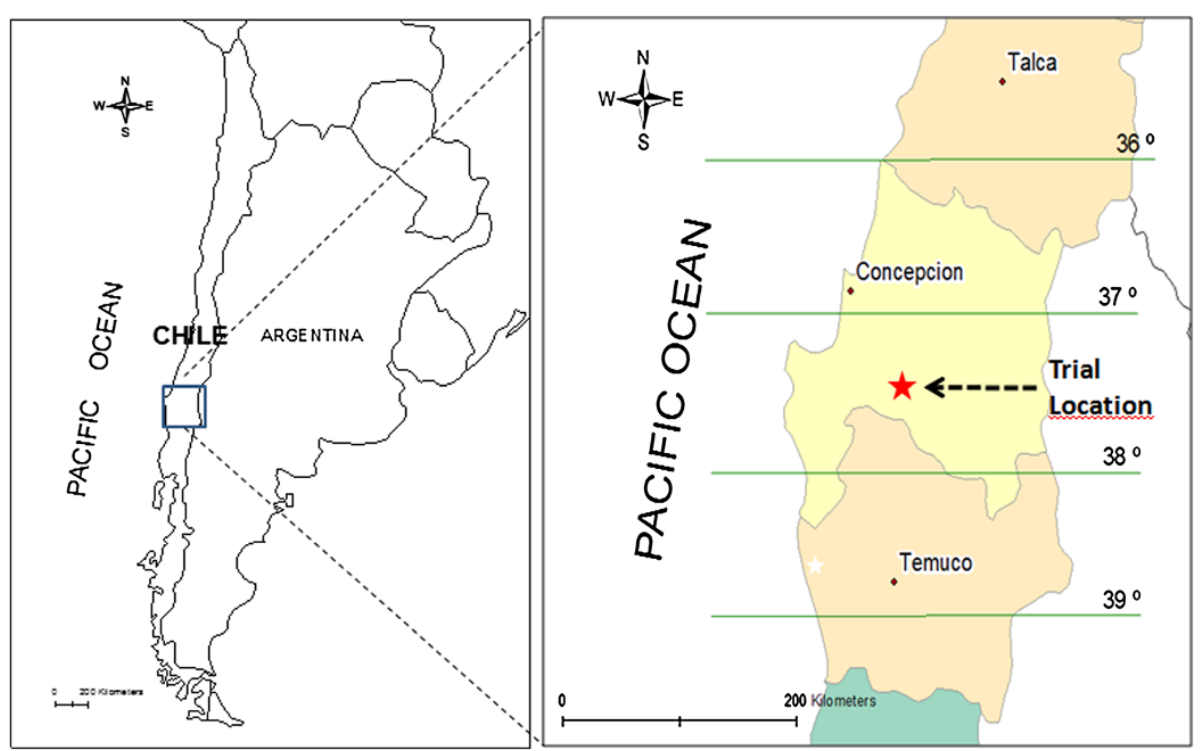

Figure 1 Map showing the location of the trial.

globulus). Trial units consisted of four contiguous plants established in a planting line. Different species/crosses were assigned randomly to trial units within each block $(1-3)$. Genetic material consisted of selections from the Forestal Mininco Eucalyptus tree-improvement programme.

Plants of homogeneous size (2-3 mm root collar diameter and $30 \mathrm{~cm}$ height) for each species/cross were selected from seven-month-old nursery material. Plants were established at a stand density of 1,666 trees ha ${ }^{-1}$ which equates to a spacing of $2 \times 3 \mathrm{~m}$. Broadcast chemical weed control was applied before and three times after establishment (Glyphosate $3 \mathrm{~L} \mathrm{ha}^{-1}$, Monsanto) to maintain weed-free conditions over the two-year period of the trial.

Irrigation was applied regularly to achieve field capacity based on evapotranspiration records from a Class-A evaporation pan (McMahon et al. 2013). The irrigation treatment was applied from September to March during both years using $1.6 \mathrm{~L} \mathrm{~h}^{-1}$ drippers inserted every $33 \mathrm{~cm}$ on a plastic pipe line that ran parallel to the planting line at a distance of $15 \mathrm{~cm}$. The total irrigation applied during the spring and summer months was $508.3 \mathrm{~mm}$ during the first year (from October 2008 to March 2009) and $329.7 \mathrm{~mm}$ during the second year (from September 2009 to March 2010).

To avoid any potential nutrient limitations, plants were fertilised with $30 \mathrm{~g}$ of a controlled release fertiliser containing $16 \% \mathrm{~N}+8 \% \mathrm{P}_{2} \mathrm{O}_{5}+12 \% \mathrm{~K}_{2} \mathrm{O}+2 \% \mathrm{MgO}+$ $5 \% \mathrm{SO}_{2}+0.4 \% \mathrm{Fe}+0.05 \% \mathrm{Cu}+0.06 \% \mathrm{Mn}+0.02 \% \mathrm{Zn}+$ $0.02 \% \mathrm{~B}+0.02 \%$ Mo. During the first season, an additional $3 \mathrm{~L} \mathrm{ha}^{-1}$ input of $3 \mathrm{mg} \mathrm{L}^{-1} \mathrm{~N}+3 \mathrm{mg} \mathrm{L}^{-1} \mathrm{P}_{2} \mathrm{O}_{5}+$ $3 \mathrm{mg} \mathrm{L}^{-1} \mathrm{~K}_{2} \mathrm{O}+3 \mathrm{mg} \mathrm{L}^{-1} \mathrm{MgO}+3 \mathrm{mg} \mathrm{L}^{-1} \mathrm{~S}+3 \mathrm{mg} \mathrm{L}^{-1}$ FeEDTA $+3 \mathrm{mg} \mathrm{L}^{-1} \mathrm{Cu}+3 \mathrm{mg} \mathrm{L}^{-1} \mathrm{Mn}+3 \mathrm{mg} \mathrm{L}^{-1} \mathrm{Zn}+$ $3 \mathrm{mg} \mathrm{L}^{-1} \mathrm{~B}+3 \mathrm{mg} \mathrm{L}^{-1}$ Mo was applied as liquid fertiliser.

\section{Measurements}

Measurements of two trees from each trial unit were obtained approximately every three weeks over two growing seasons from late spring (4 November) 2008 to

Table 1 Average physical and chemical soil properties sampled from two soil pits ( $1 \mathrm{~m} \times 1 \mathrm{~m} \times 1 \mathrm{~m}$ dimension) located in the area before establishment of the trial

\begin{tabular}{|c|c|c|c|c|c|c|c|c|c|c|c|}
\hline \multirow[t]{2}{*}{ Soil horizon } & \multirow{2}{*}{$\begin{array}{l}\text { Depth } \\
(\mathrm{cm})\end{array}$} & \multirow{2}{*}{$\begin{array}{l}\text { Coarse fragments } \\
(\%)\end{array}$} & \multirow{2}{*}{$\begin{array}{l}\text { Bulk density } \\
\left(\mathrm{g} \mathrm{cm}^{-3}\right)\end{array}$} & PWP & $\mathrm{FC}$ & \multirow{2}{*}{$\frac{\mathrm{pH}}{1: 2.5}$} & \multirow{2}{*}{$\frac{\mathrm{OM}}{\%}$} & $\mathbf{N}$ & $\mathbf{P}$ & $\mathrm{K}$ & B \\
\hline & & & & --- o & & & & \multicolumn{4}{|c|}{-- $\left(\mathrm{mg} \mathrm{Kg}^{-1}\right)$} \\
\hline A & 5 & 0 & 0.7 & 24.3 & 44.7 & 5.5 & 7.6 & 41 & 5.3 & 250 & 1.3 \\
\hline BA & 15 & 0 & 1.1 & 22.0 & 42.1 & 5.3 & 5.9 & 38 & 0.75 & 75 & 1.0 \\
\hline B1 & 33 & 5 & 1.1 & 20.3 & 42.1 & 5.7 & 2.3 & 22 & 0.28 & 25 & 0.3 \\
\hline B2 & $33-100$ & 10 & 1.2 & 23.9 & 43.5 & 5.3 & 4.2 & 24 & 1.05 & 33 & 0.8 \\
\hline
\end{tabular}

PWP: Permanent wilting point; FC: Field capacity; $\mathrm{pH}$ : acidity determined on a 1:2.5 soil:water ratio; OM: organic matter determined by LOI at $450^{\circ} \mathrm{C} ; \mathrm{N}$ : Available $\mathrm{N}$ extracted with $2 \mathrm{M} \mathrm{KCl}$ and determined by titration; $\mathrm{P}$ : soil available phosphorus Olsen extraction and determined colorimetrically; $\mathrm{K}$. available soil potassium via ammonium acetate extraction and determined via atomic absorption spectrometry; B: available boron extracted with hot water and determined colorimetrically. 
mid-winter (31 July) 2010. Tree height $(H)$ and diameter $(D)$ at $10 \mathrm{~cm}$ height above the ground line were measured. A volume index, $V$, was determined from these measurements as,

$$
V=0.33 \pi\left(D^{2} / 4\right) H
$$

Daily minimum, mean and maximum air temperatures were collected from a weather station (Davies Instruments Co.) located $140 \mathrm{~m}$ from the trial.

\section{Data analyses}

All analyses were undertaken using SAS software (SAS Institute Inc. 2008). Growth in $V$ over two years was modelled using block-level measurements. To achieve this, Equation 4 was applied using a daily step length with the modifier described in Equation 5 calculated using measurements of daily mean air temperature. This calculation provided daily predictions of $V$ that could be compared against measured $V$ at each assessment date. The model parameters for Equations 4 and 5 were estimated so as to minimise the sum of squares of differences between predicted and measured values, with separate parameters being obtained for each block $\times$ species/cross combination. This analysis was carried out using the SAS NLIN procedure. Model fit was assessed by the root mean square error (RMSE) and coefficient of determination $\left(R^{2}\right)$.

This procedure provided estimates of the model parameters $a, b, T_{b}, T_{o}$, and $T_{c}$ for each block $\times$ species/ cross. Attempts were also made to obtain estimates for parameter $c$ (Equation 5). However, model convergence was generally not achieved when fitting $c$. It was found that the RMSE was lowest at $c=2$ when $c$ was kept fixed to a global value across all species/crosses, although there was little change in the RMSE for all values of $c$ between 1 and 10. However, the RMSE increased when $c$ was less than 1, both across all species/crosses and for each individual species/cross. A fixed value of $c=2$ was, therefore, used in all models.

Plots of modifier against temperature were not symmetrical for the range studied. The values at which $m=$ 0.05 in the lower and upper part of the distribution were determined to avoid the effects of long tails in the plots of the modifier $(m)$ against temperature. These two values are referred to, as $T_{b}{ }^{\prime}$ and $T_{c}^{\prime}$ respectively. These values appeared to give a better indication of the base and ceiling temperatures than $T_{b}$ and $T_{c}$, as they showed greater consistency between blocks for each species/ cross, and lower error sums of squares in analyses of variance comparing species/crosses. The parameters $T_{b}$ ' and $T_{c}{ }^{\prime}$ were estimated using an iterative procedure detailed in Appendix 1.
One-way analyses of variance fitted using the SAS procedure MIXED were used to test for significant species/ cross differences in the model parameters $a, b, T_{b}, T_{o}, T_{c}$, mean values for the air temperature modifier, $m$, the adjusted base and ceiling temperatures $T_{b}{ }^{\prime}$ and $T_{c}$, and plant size $(H, D$ and $V)$ at the end of the trial. Multiple comparisons between the different species/crosses were undertaken using Tukey's method as implemented in the SAS mixed model procedure.

\section{Results}

\section{Site range in air temperature}

There was wide annual variation in mean air temperature at the site with air temperature peaking in late summer and reaching minimum values during mid-winter (Figure 2a). The overall minimum and maximum daily air temperatures recorded over the period of the study were -3.7 and $37.7^{\circ} \mathrm{C}$, respectively. A total of 39 frosts were recorded. The mean daily temperature over the period of the study averaged $13.0^{\circ} \mathrm{C}$ and ranged from $0.27^{\circ} \mathrm{C}$ to $26.12^{\circ} \mathrm{C}$ (Figure 2a).

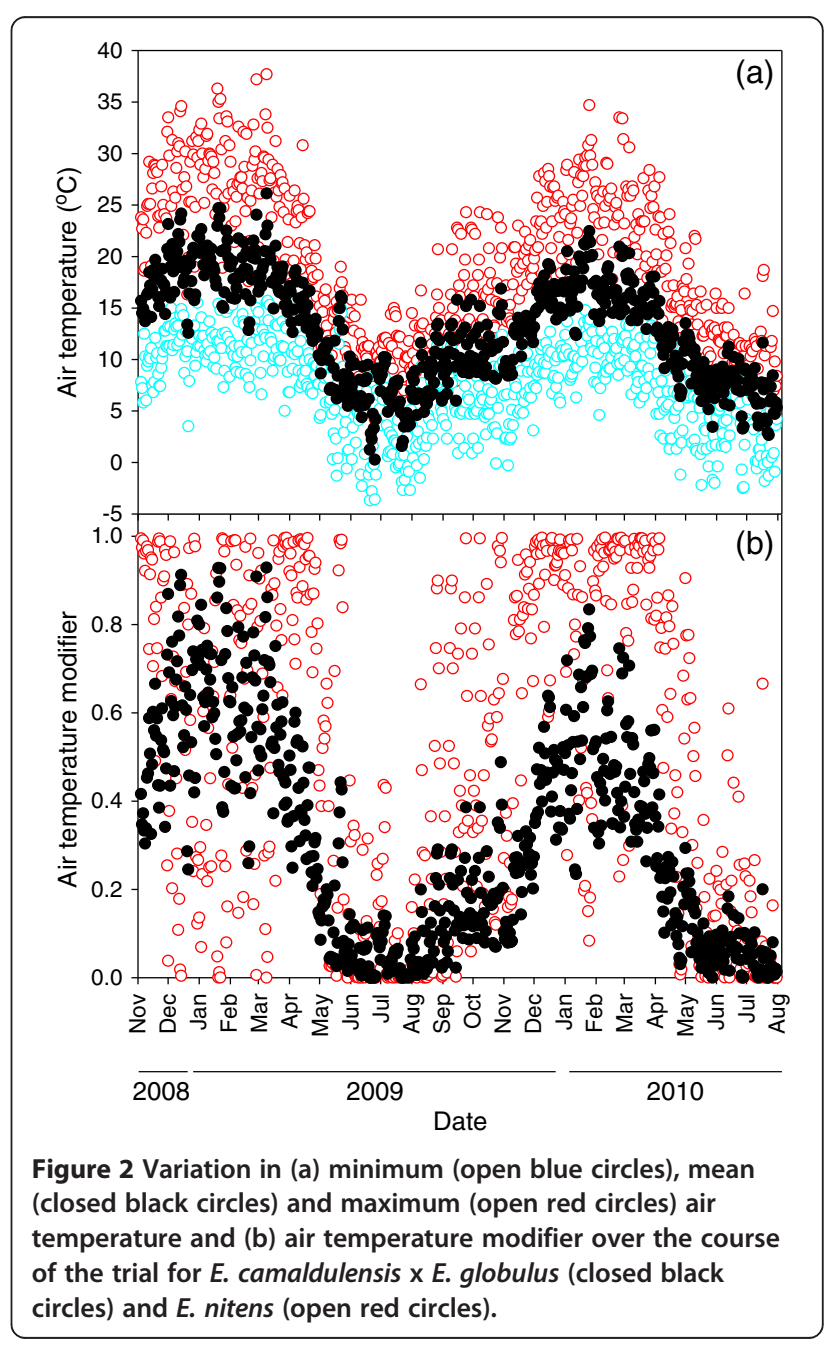




\section{Variation in tree dimensions}

Tree height, diameter and volume index varied widely among the five species/crosses (Figure $3 a, b$ and c, respectively). Changes in dimensions over the two years exhibited marked seasonal variation and an exponential increase between the first and second year occurred for both $H$ and $V$ (Figure 3a and c). Significant species/cross differences were observed by the end of the trial for $H$ $(P=0.0141), D(P=0.0002)$ and $V(P<0.0001)$. Species $/$ cross variation at the end of the trial was most marked for $V$, which ranged three-fold between the poorest performing cross, E. camaldulensis x E. globulus and the best performing species, E. nitens (Figure 3c; Table 2).

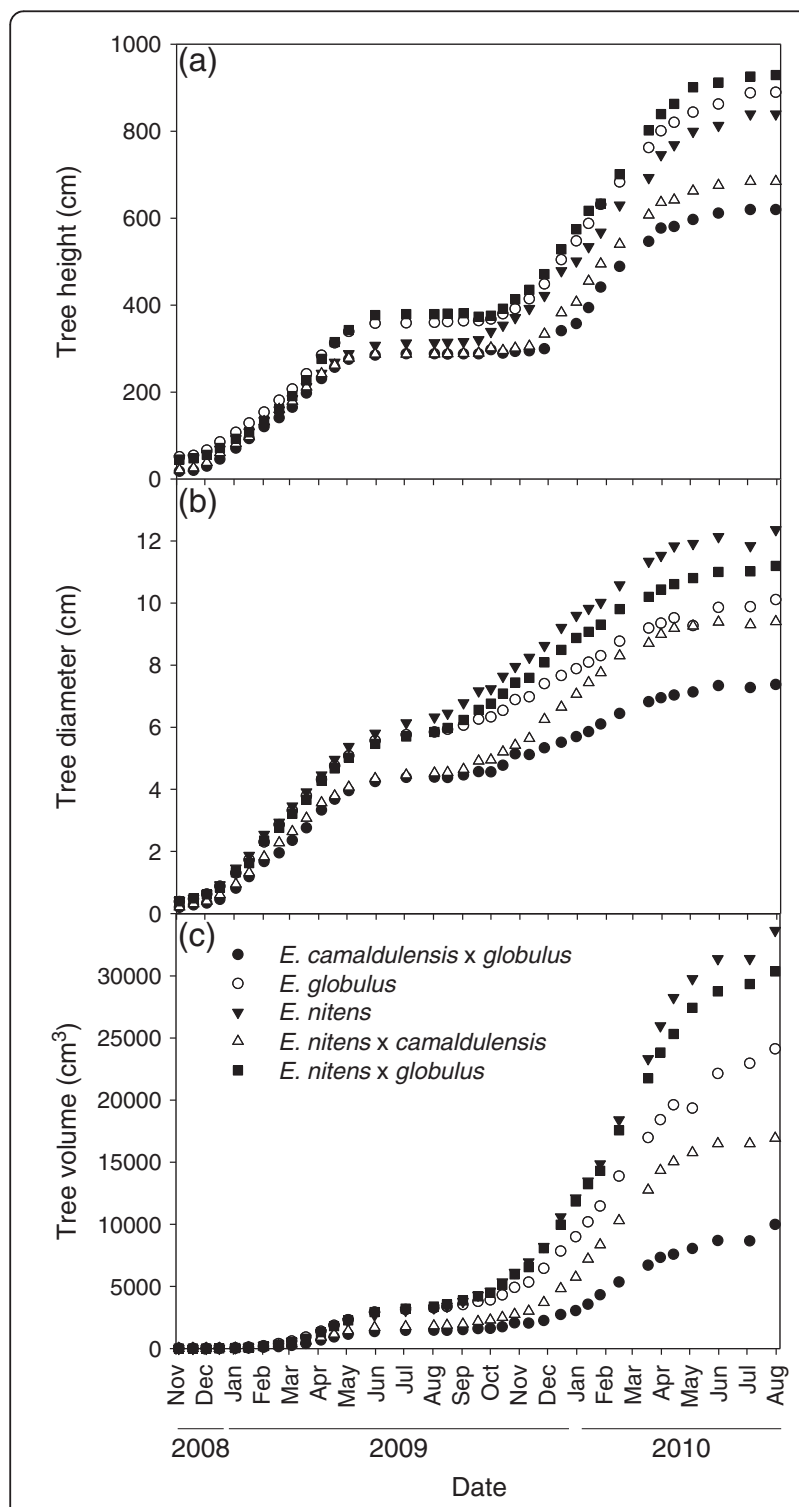

Figure 3 Variation in (a) tree height, (b) tree diameter and (c) tree volume index over the course of the trial for the five Eucalyptus species/crosses. Each value shown is the mean of three blocks.

\section{Model fit}

The model predictions corresponded well to the actual data for all species/cross $\mathrm{x}$ block combinations (see Additional file 1 for fit statistics). Across the 15 combinations examined, the coefficient of determination ranged from 0.993 to 0.999 , averaging 0.998 . The RMSE was very low, ranging from $111 \mathrm{~cm}^{3}$ to $657 \mathrm{~cm}^{3}$ and averaged $370 \mathrm{~cm}^{3}$ (Additional file 1). Little apparent bias in model fit was evident against month as shown for block-level means of the two species/crosses representing the extremes in growth, E. camaldulensis x E. globulus (Figure 4a-c) and E. nitens (Figure 4d-f).

\section{Model parameters}

Highly significant species/cross differences were found for the fitted values of $T_{o}$ (Table 2). The $T_{o}$ for $E$. camaldulensis x E. globulus of $26.9^{\circ} \mathrm{C}$ significantly exceeded that of all other species/crosses, where $T_{o}$ ranged from 15.4 to $18.7^{\circ} \mathrm{C}$ (Table 2; Figure 5 ). The parameter $T_{b}$ varied from $3.2^{\circ} \mathrm{C}$ to $6.2^{\circ} \mathrm{C}$ but this difference was not statistically significant. Although variation in parameter $T_{c}$ was relatively wide, standard errors were high, and only the two extreme species/crosses ( $E$. nitens $\mathrm{x} E$. globulus at $21.6^{\circ} \mathrm{C}$ and E. camaldulensis x E. globulus at $29.8^{\circ} \mathrm{C}$ ) differed significantly.

The derived metric $T_{b}$ ' did not differ significantly among species/crosses, ranging from 6.4 to $7.4^{\circ} \mathrm{C}$ (Table 2; Figure 5). The derived metric $T_{c}$ ' for E. camaldulensis x E. globulus with a value of $29.8^{\circ} \mathrm{C}$ was significantly higher than that of the other species/crosses which ranged between 21.1 to $22.7^{\circ} \mathrm{C}$. The temperature difference between the derived metrics $T_{b}{ }^{\prime}$ and $T_{c}{ }^{\prime}$ was greatest for E. camaldulensis x E. globulus $\left(22.4^{\circ} \mathrm{C}\right)$ followed by $E$. globulus $\left(16.3^{\circ} \mathrm{C}\right)$, E. nitens x camaldulensis $\left(16.1^{\circ} \mathrm{C}\right)$, E. nitens $\left(14.8^{\circ} \mathrm{C}\right)$ and E. nitens $\mathrm{x}$ E. globulus $\left(13.9^{\circ} \mathrm{C}\right)$ (Figure 5).

\section{Air temperature modifier and response function}

The air temperature response function varied markedly between E. camaldulensis x E. globulus and the other four eucalypt species/crosses (Figure 6). The parameter $T_{o}$ for $E$. camaldulensis $\mathrm{x} E$. globulus was close to the highest mean daily air temperature recorded during the study (dotted line, Figure 6). As a result, the air temperature modifier was almost always sub-optimal for this cross (Figure 2b), with peaks corresponding to higher air temperatures (Figure 2b) in late summer. In contrast, $T_{o}$ for other functions were considerably closer to the mean air temperature of the site (Table 2), with $T_{o}$ for $E$. nitens most closely approximating the mean site air temperature $\left(15.4\right.$ vs. $\left.13.0^{\circ} \mathrm{C}\right)$. As a result, the air temperature modifier for $E$. nitens exhibited dual peaks during late spring/early summer and then again in early autumn when air temperatures were closest to $T_{o}$ (Figure $2 \mathrm{~b}$ ). 
Table 2 Species/cross variation in final stem volume index growth, model parameters and values derived from the fitted model

\begin{tabular}{|c|c|c|c|c|c|c|}
\hline & \multicolumn{5}{|c|}{ Species/cross $^{1}$} & \multirow{2}{*}{$\begin{array}{l}\text { Analyses of } \\
\text { variance }\end{array}$} \\
\hline & E. c. $\times$ E. g. & E. n. x E. c. & E. $g$. & E. n. x E. g. & E. $n$. & \\
\hline \multicolumn{7}{|l|}{ Parameters } \\
\hline$a$ & 63,539 & 34,336 & 27,962 & 49,973 & 44,745 & $1.73^{\mathrm{ns}}$ \\
\hline$b$ & $3.11 \mathrm{a}$ & $2.84 \mathrm{ab}$ & $2.52 \mathrm{~b}$ & $2.43 \mathrm{ab}$ & $2.61 \mathrm{ab}$ & $3.78^{*}$ \\
\hline$T_{b}\left({ }^{\circ} \mathrm{C}\right)$ & 3.2 & 4.4 & 4.7 & 5.9 & 6.2 & $1.59^{\mathrm{ns}}$ \\
\hline$T_{0}\left({ }^{\circ} \mathrm{C}\right)$ & $26.9 a$ & $18.7 \mathrm{~b}$ & $16.7 \mathrm{~b}$ & $15.7 \mathrm{~b}$ & $15.4 \mathrm{~b}$ & $17.84^{* * *}$ \\
\hline$T_{C}\left({ }^{\circ} \mathrm{C}\right)$ & 29.8 a & $22.8 \mathrm{ab}$ & $23.0 \mathrm{ab}$ & $21.6 b$ & $23.1 \mathrm{ab}$ & $3.69^{*}$ \\
\hline \multicolumn{7}{|l|}{ Derived metrics } \\
\hline$T_{b}^{\prime}\left({ }^{\circ} \mathrm{C}\right)$ & 7.4 & 6.6 & 6.4 & 7.2 & 7.4 & $0.56^{\mathrm{ns}}$ \\
\hline$T_{c}^{\prime}\left({ }^{\circ} \mathrm{C}\right)$ & 29.8 a & $22.7 \mathrm{~b}$ & $22.7 \mathrm{~b}$ & $21.1 \mathrm{~b}$ & $22.2 \mathrm{~b}$ & $5.25^{*}$ \\
\hline Mean $m$ & $0.292 \mathrm{a}$ & $0.461 \mathrm{~b}$ & $0.535 \mathrm{~b}$ & $0.465 b$ & $0.491 \mathrm{~b}$ & $8.12^{* *}$ \\
\hline Final $V\left(\mathrm{~cm}^{3}\right)$ & $9,256 \mathrm{a}$ & $21,188 \mathrm{~b}$ & $26,780 \mathrm{bc}$ & $30,360 \mathrm{~cd}$ & $33,649 d$ & $61.28^{* * *}$ \\
\hline
\end{tabular}

Derived values include the air temperature modifier $(m)$ averaged over the trial duration and the temperatures at which $m=0.05$ in the lower $\left(T_{b}\right)$ and upper $\left(T_{c}\right)$ parts of the distribution. Each value shown is the mean of three blocks. For the analysis the $F$ values are given followed by the $P$-category. Asterisks ***,**and * denote significance at $P=0.001,0.01$ and 0.05 respectively; ns represents not significant at $P=0.05$. Values in a row followed by the same letter do not significantly differ. ${ }^{1} E$. g. $=$ Eucalyptus globulus; E. c. = Eucalyptus camaldulensis; E. n. = Eucalyptus nitens.

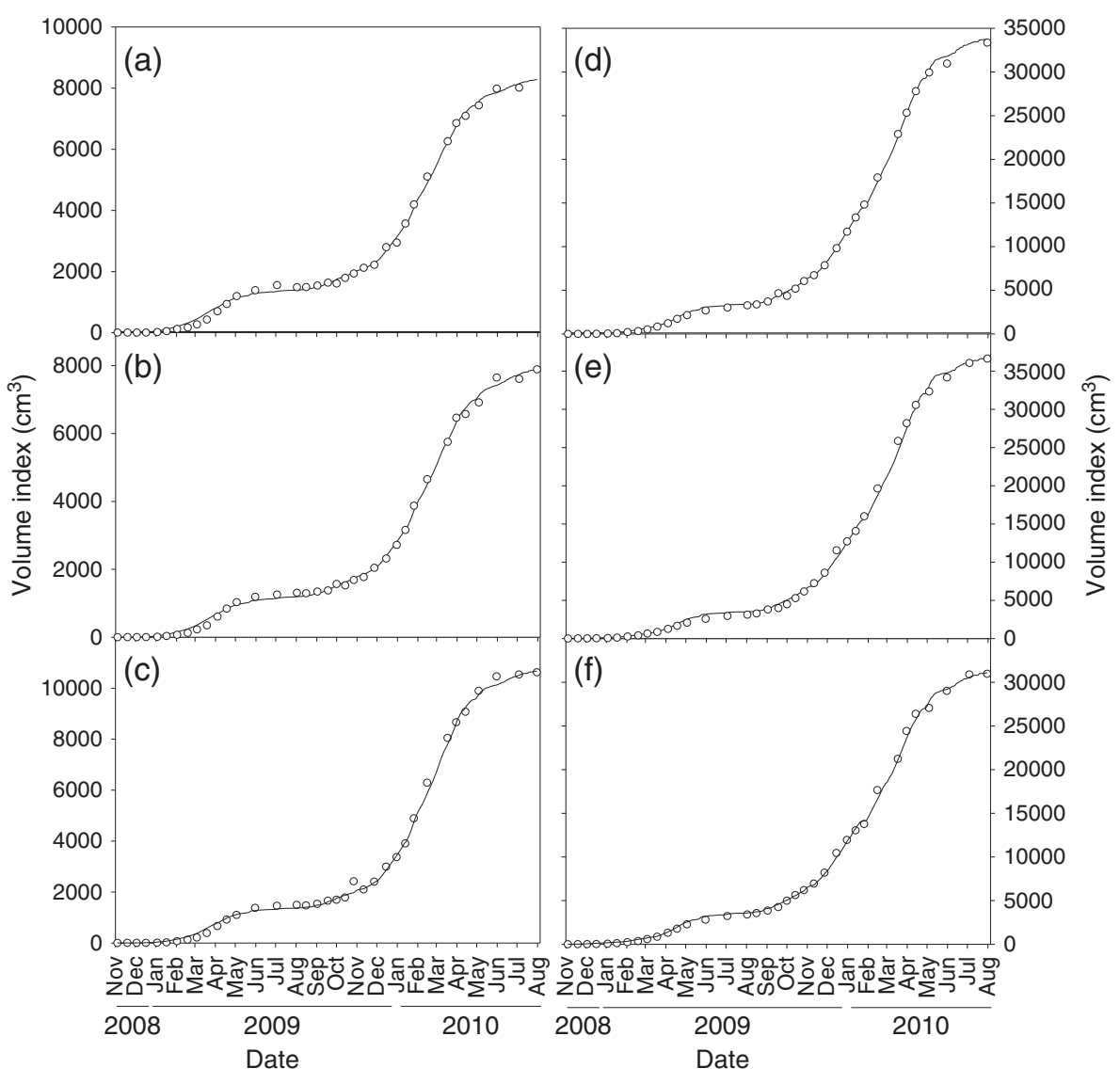

Figure 4 Variation in measured (symbols) and modelled (line) volume index for E. camaldulensis $x$ E. globulus (left hand figures) and E. nitens (right hand figures) over the course of the trial for trees in block 1 (a, d), block 2 (b, e) and block 3 (c, f). 


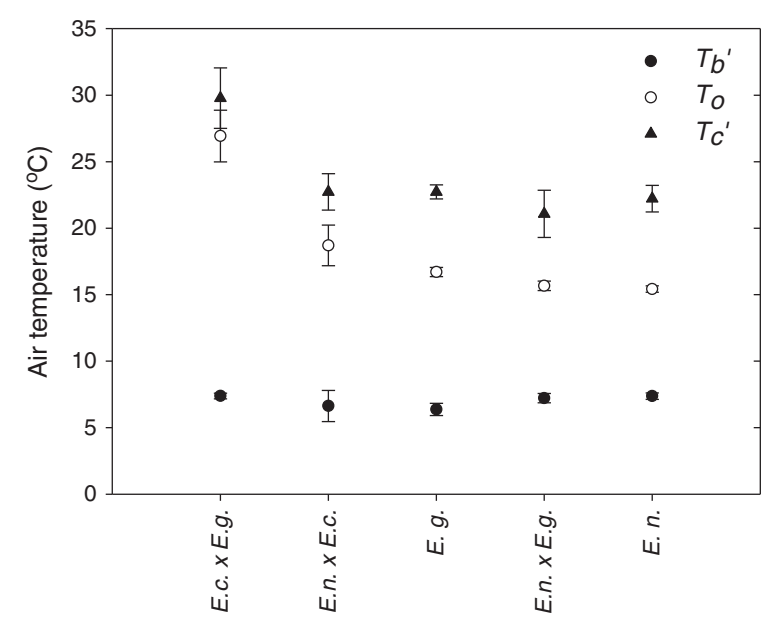

Figure 5 Variation in $T_{b}{ }^{\prime}$ (filled circles), $T_{o}$ (open circles), and $T_{c}{ }^{\prime}$ (filled triangles) among species/crosses. Shown are the mean and standard errors from the three blocks. E. g. = Eucalyptus globulus; E. c. = Eucalyptus camaldulensis; E. $n$. $=$ Eucalyptus nitens.

The mean value of the air temperature modifier was significantly lower for the E. camaldulensis x E. globulus (0.292) cross than all other species/crosses and highest for the species E. globulus (0.535) and E. nitens (0.491) (Table 2).

\section{Discussion}

The model described in this paper provides a simple method for estimating cardinal air temperatures of tree species used in plantation forestry. A major advance is that this method can be used to normalise the effect of changing plant size on expected growth so that the growth response

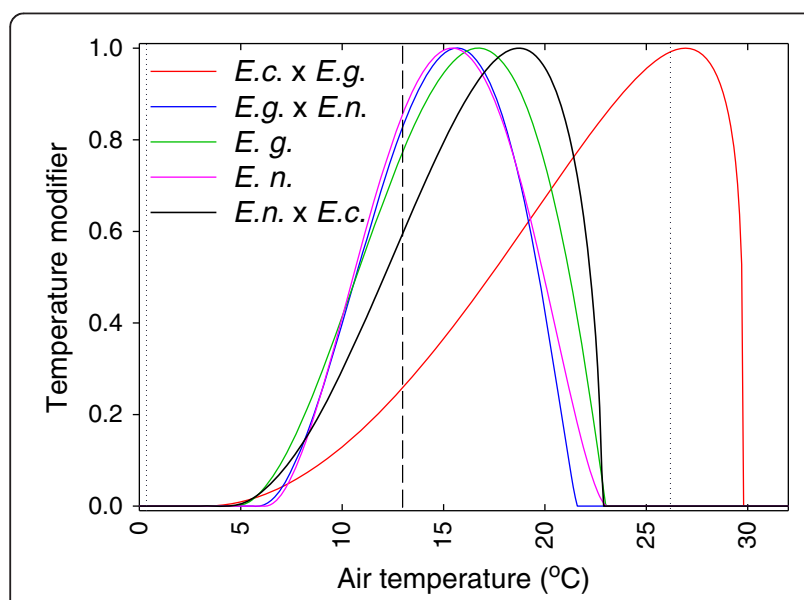

Figure 6 The air temperature response function for all species/ crosses tested. Values shown are derived from model parameters for each species/cross averaged across all three blocks. Also shown are the minimum mean (left-hand dotted line), mean (dashed line) and maximum mean (right-hand dotted line) daily air temperature for the site. to air temperature can be more clearly defined. The utility of this modelling method was demonstrated by the close correspondence between empirical measurements and estimated values of growth for the five Eucalyptus species/ crosses to which the model was fitted.

This model can be used to estimate how well a species will be suited to a particular site. In this study, the site was abundantly irrigated and fertilised, and hence air temperature was the dominant environmental factor affecting site suitability for each species. Both the proximity of $T_{o}$ to the mean site air temperature and the range between $T_{c}$ ' and $T_{b}$ ' are important factors affecting suitability of each species to the site. Eucalyptus nitens, E. globulus and the cross between these two species were most closely adapted to this particular site as $T_{o}$ for these species were relatively close to the mean site air temperature. Compared to $E$. nitens and the E. nitens $\mathrm{x}$ E. globulus cross, there was a greater range between $T_{c}$, and $T_{b}^{\prime}$ for E. globulus that allowed greater growth at sub- and supra-optimal air temperatures resulting in a higher value of the temperature modifier for this latter species. Clearly, E. camaldulensis x E. globulus was not well adapted to the site. Although this cross had the widest range between $T_{c}{ }^{\prime}$ and $T_{b}$ ' of the trial species/ crosses tested, $T_{o}$ was substantially higher than the mean air temperature of the site and relatively close to the highest mean daily air temperature recorded on the site. Consequently, growth was almost always sub-optimal for this cross.

The optimal air temperatures described here are consistent with previous research describing climatic requirements of different Eucalyptus species. Eucalyptus camaldulensis has been found to be most suited to climates with mean annual air temperatures ranging from $18-28^{\circ} \mathrm{C}$ for the northern province and $13-22^{\circ} \mathrm{C}$ for the southern provenance. In contrast, $E$. nitens and $E$. globulus are more suited to cooler climates with optimal mean annual air temperatures ranging from $9-18^{\circ} \mathrm{C}$ (Booth and Pryor 1991).

The model described here can be used to account for complex variation in seasonal growth patterns between species. For E. nitens, the temperature modifier had high values over a broad time period with dual peaks occurring either side of mid and late summer (data not shown), when air temperatures were close to the optimum. The characterisation of these dual peaks by the model represents a refinement over previous, more empirical methods (e.g. use of a sine curve linked to Julian day) that can only be used to simulate a single growth peak throughout the growing season. In contrast, as $T_{o}$ was very close to the highest mean daily air temperature for E. camaldulensis x E. globulus, the phenology of this cross closely tracked the daily air temperature of the site peaking in mid to late summer. 
Although the model described here only included air temperature, other important growth limiting variables, such as soil moisture, could be readily added to this framework. These variables could be introduced into the model as response functions that affect values of the modifier $(m)$ in a similar manner to that of air temperature, arranged in accordance with the ecological Law of the Minimum (reviewed by van der Ploeg et al. 1999). A suitable response function should accord with the Law of Tolerance (reviewed in Shelford 1963). Fitting the response function to data should allow extraction of cardinal values for variables such as fractional available volumetric water content, $\theta$, (i.e. minimum, optimum and maximum $\theta$ for plant growth) to be estimated.

The type of model described here is likely to be useful for producing robust maps that describe species growth and areas of optimal suitability (e.g., the annual Growth Index, $\mathrm{GI}_{\mathrm{A}}$ in CLIMEX, Sutherst et al. 2007). Such models have often had to rely upon informed guesses for parameters describing the soil moisture and air temperature growth response functions. Some CLIMEX and DYMEX (Maywald et al. 2007) models have employed growth responses that have been parameterised based on trial observations (Kriticos et al. 2009), few have used phenological observations to infer cardinal temperatures (De Villiers et al. 2012), and none that we know of have involved perennial species.

A key issue facing any grower of commercial agricultural or forestry crops is to understand how best to match species or genotypes to a particular site. Often there is insufficient information on which to base these decisions particularly for different genotypes of the same species. The methodology described here could greatly simplify this process as cardinal air temperatures can be defined for all species and genotypes of interest from a single trial. Using these cardinal temperatures in simple growth index models such as CLIMEX, maps describing growth could then be developed from underlying climatological datasets. The optimal species for each grid cell in a given area could be extracted by overlaying a number of these maps and selecting the most economically attractive species based on growth rates and relevant market information. As spatial information describing climate is available at a range of resolution and spatial extent such maps could be generated at scales ranging from local to global.

There were limitations within the dataset that should be taken into account when interpreting the results. The sample size was relatively small and measurements were taken from a single trial over a relatively short time period on juvenile trees. Use of a dataset covering a greater environmental range and trees that are older is likely to produce more robust estimates of cardinal air temperatures. Results show that $T_{b}$ ' and $T_{o}$ were precisely estimated for all species. However, values of $T_{c}$ ' were less precisely estimated, particularly for the E. camaldulensis x E. globulus cross as the highest mean daily air temperature was lower than $T_{\mathrm{c}}$ '. The reported values for $T_{\mathrm{c}}$ ' were also markedly lower than values reported previously for E. globulus and E. nitens (Sands and Landsberg 2002; Fontes et al. 2006; PerezCruzado et al. 2011). This highlights the need for careful placement of trials in climates where the natural range in air temperature covers the expected range of $T_{b}{ }^{\prime}-T_{c}{ }^{\prime}$ for the species/crosses being evaluated. Covering this range may require installation of more than one trial in locations with contrasting climates. Despite these dataset limitations we consider the methodology to provide a robust means of determining cardinal air temperatures of different species.

\section{Conclusions}

The methodology outlined in this paper describes how data from simple trials can be effectively used within a model to gain considerable insight into plantation crop species climatic preferences. Adoption of such an approach could augment or replace extensive and costly trial networks that need to be monitored over long time periods. Further research should extend the described modelling approach to situations where other environmental factors such as root-zone water storage limit growth. Inclusion of a frost modifier within the modelling framework may also improve the predictive precision and provide insight into how different species respond to frost.

\section{Appendix 1 Iterative procedure for estimating $T_{b}{ }^{\prime}$ and $T_{c}^{\prime}$}

Because plots of the modifier (Equation 5) against $c$ can have long tails, especially for large values of $c, T_{b}$ and $T_{c}$ can sometimes provide exaggerated base and ceiling temperatures. Better representations of these temperatures may be indicated by the temperatures at which the modifier $m$ equals some small value $h$, say $h=0.05$. These modified base and ceiling temperatures are represented by $T_{b}$ ' and $T_{c}$ ' respectively. The following iterative procedure can be used to calculate them.

Let, $k=\left(T_{c}-T_{o}\right) /\left(T_{o}-T_{b}\right)$,

and, $l=h^{1 / c}\left(T_{o}-T_{b}\right)\left(T_{c}-T_{o}\right)^{k}$

Starting with $L_{O}=0$ and $U_{O}=0$, perform the following iterations for $i=1,2, \ldots$ until convergence is achieved for $U$ and $L$ :

$$
L_{i+1}=l /\left(\left(T_{c}-T_{b}\right)^{k+1}\left(1-L_{i}\right)^{k}\right)
$$

and, $U_{i+1}=\left(l /\left(\left(T_{c}-T_{b}\right)^{k+1}\left(1-U_{i}\right)\right)\right)^{1 / k}$

Finally, calculate $T_{b}{ }^{\prime}$ and $T_{c}{ }^{\prime}$ as follows: $T_{b}^{\prime}=T_{b}+L$ $\left(T_{c}-T_{b}\right)$ and, $T_{b}^{\prime}=T_{c}-U\left(T_{c}-T_{b}\right)$ 


\section{Additional file}

\section{Additional file 1: Model fit statistics, parameter values, derived values and final measured volume index growth for all block - species/cross combinations.}

\section{Competing interests}

The authors declare that they have no competing interests.

\section{Authors' contributions}

MSW was the primary author and assisted with analysis of the data. RR designed and managed the trial used within the study, assisted with data processing and was a secondary author. MOK developed the final model and undertook the majority of the analyses. DJK was a secondary author. VE, $\mathrm{OM}, \mathrm{MA}, \mathrm{MP}$, JS, TF assisted with trial design and measurements. All authors read and approved the final manuscript.

\section{Acknowledgements}

This research was funded and supported by FONDECYT project No 1085093 , Forestal Mininco S.A. and the Faculty of Forest Sciences at the Universidad de Concepción.

\section{Author details}

${ }^{1}$ Scion, PO Box 29237, Fendalton, Christchurch, New Zealand. Depto. Silvicultura, Facultad de Ciencias Forestales, Universidad de Concepción, Casilla 160-C, Correo 3, Concepción, Chile. ${ }^{3}$ Scion, PO Box 3020, Rotorua, New Zealand. ${ }^{4} \mathrm{CSIRO}$ Ecosystem Sciences and Climate Adaptation Flagship, GPO Box 1700, Canberra ACT 2601, Australia. ${ }^{5}$ Forestal Mininco S.A, Avenida Alemana 751, Los Angeles, Chile. ${ }^{6}$ Department of Forestry and Environmental Resources, Box 8008, North Carolina State University, Raleigh, NC 27695-8008, USA. ${ }^{7}$ Department of Forestry, 228 Cheatham Hall, Virginia Polytechnic Institute and State University, Blacksburg, VA 24060, USA. ${ }^{8}$ Instituto Forestal Sede Concepción, Concepción, Chile.

\section{Received: 12 December 2013 Accepted: 20 February 2014}

\section{Published online: 11 June 2014}

\section{References}

Almeida, AC, Landsberg, JJ, \& Sands, PJ. (2004a). Parameterisation of 3-PG model for fast-growing Eucalyptus grandis plantations. Forest Ecology and Management, 193(1-2), 179-195.

Almeida, AC, Landsberg, JJ, Sands, PJ, Ambrogi, MS, Fonseca, S, Barddal, SM, \& Bertolucci, FL. (2004b). Needs and opportunities for using a process-based productivity model as a practical tool in Eucalyptus plantations. Forest Ecology and Management, 193(1-2), 167-177.

Battaglia, M, \& Sands, P. (1997). Modelling site productivity of Eucalyptus globulus in response to climatic and site factors. Australian Journal of Plant Physiology, 24(6), 831-850

Battaglia, M, Beadle, C, \& Loughhead, S. (1996). Photosynthetic temperature responses of Eucalyptus globulus and Eucalyptus nitens. Tree Physiology, 16(1-2), 81-89.

Battaglia, M, Sands, PJ, \& Candy, SG. (1999). Hybrid growth model to predict height and volume growth in young Eucalyptus globulus plantations. Forest Ecology and Management, 120(1-3), 193-201. doi:10.1016/S0378-1127(98)00548-9.

Battaglia, M, Sands, P, White, D, \& Mummery, D. (2004). CABALA: a linked carbon, water and nitrogen model of forest growth for silvicultural decision support Forest Ecology and Management, 193(1/2), 251-282.

Besoain, ME. (1985). Los suelos, Capítulo 1 (pp. 24-106). En: Suelos Volcanicos de Chile. Instituto de Investigaciones Agropecuarias-INIA. Santiago.

Bollmann, MP, Sweet, GB, Rook, DA, \& Halligan, EA. (1986). The Influence of temperature, nutrient status, and short drought on seasonal Initiation of primordia and shoot elongation in Pinus radiata. Canadian Journal of Forest Research-Revue Canadienne De Recherche Forestiere, 16(5), 1019-1029.

Booth, TH, \& Pryor, LD. (1991). Climatic requirements of some commercially important eucalypt species. Forest Ecology and Management, 43, 47-60.

Campoe, OC, Stape, JL, Albaugh, TJ, Allen, HL, Fox, TR, Rubilar, R, \& Binkley, D. (2013). Fertilization and irrigation effects on tree level aboveground net primary production, light interception and light use efficiency in a loblolly pine plantation. Forest Ecology and Management, 288, 43-48. doi:10.1016/j.foreco.2012.05.026.

De Villiers, M, Hattingh, V, \& Kriticos, DJ. (2012). Combining field phenological observations with distribution data to model the potential range distribution of the fruit fly Ceratitis rosa Karsch (Diptera: Tephritidae). Bulletin of Entomological Research, 103, 60-73. doi:10.1016/S0378-1127(01) 00802-7.

Duchesne, L, \& Houle, D. (2011). Modelling day-to-day stem diameter variation and annual growth of balsam fir (Abies balsamea (L.) Mill.) from daily climate. Forest Ecology and Management, 262(5), 863-872. doi:10.1016/j.foreco.2011.05.027.

Dumar, D, Pilbeam, CJ, \& Craigon, J. (1990). Use of the Weibull function to calculate cardinal temperatures in faba bean. Journal of Experimental Botany, $41,1423-1430$

Esprey, LJ, Sands, PJ, \& Smith, CW. (2004). Understanding 3-PG using a sensitivity analysis. Forest Ecology and Management, 193, 235-250.

Fontes, L, Landsberg, J, Tomé, J, Tomé, M, Pacheco, CA, Soares, P, \& Araujo, C. (2006). Calibration and testing of a generalized process-based model for use in Portuguese eucalyptus plantations. Canadian Journal of Forest Research, 36(12), 3209-3221.

Jones, EA, Reed, DD, Cattelino, PJ, \& Mroz, GD. (1991). Seasonal shoot growth of planted red pine predicted from air-temperature degree days and soil-water potential. Forest Ecology and Management 46(3-4), 201-214.

Kimberley, MO, \& Richardson, B. (2004). Importance of seasonal growth patterns in modelling interactions between radiata pine and some common weed species. Canadian Journal of Forest Research, 34(1), 184-194.

Kirschbaum, MUF. (1999). CenW, a forest growth model with linked carbon, energy, nutrient and water cycles. Ecological Modelling, 118(1), 17-59.

Kirschbaum, MUF, \& Watt, MS. (2011). Use of a process-based model to describe spatial variation in Pinus radiata productivity in New Zealand. Forest Ecology and Management, 262(6), 1008-1019. doi:10.1016/j.foreco.2011.05.036.

Kirschbaum, MUF, Watt, MS, Tait, A, \& Ausseil, AGE. (2012). Future wood productivity of Pinus radiata in New Zealand under expected climatic changes. Global Change Biology, 18(4), 1342-1356. doi:10.1111/j.13652486.2011.02625.x.

Kriticos, DJ, Watt, MS, Withers, TM, Leriche, A, \& Watson, MC. (2009). A processbased population dynamics model to explore target and non-target impacts of a biological control agent. Ecological Modelling, 220(17), 2035-2050. doi:10.1016/j.ecolmodel.2009.04.039.

Levins, R. (1966). Strategy of model building in population biology. American Scientist, 54, 421-431.

Mason, EG, \& Dzierzon, H. (2006). Applications of modeling to vegetation management. Canadian Journal of Forest Research-Revue Canadienne De Recherche Forestiere, 36(10), 2505-2514. doi:10.1139/X06-191.

Mason, EG, Methol, R, \& Cochrane, H. (2011). Hybrid mensurational and physiological modelling of growth and yield of Pinus radiata D. Don. using potentially useable radiation sums. Forestry, 84(2), 99-108. doi:10.1093/ forestry/cpq048.

Maywald, GF, Kriticos, DJ, Sutherst, RW, \& Bottomley, W. (2007). Dymex Model Builder Version 3: User's Guide, edn. Melbourne: Hearne Publishing.

McMahon, T, Peel, MC, Lowe, L, Srikanthan, R, \& McVicar, TR. (2013). Estimating actual, potential, reference crop and pan evaporation using standard meteorological data: A pragmatic synthesis. Hydrology and Earth System Sciences, 17, 1331-1363. doi:10.5194/hess-17-1331-2013.

Medlyn, BE, Duursma, RA, \& Zeppel, MJB. (2011). Forest productivity under climate change: a checklist for evaluating model studies. Wiley Interdisciplinary Reviews-Climate Change, 2(3), 332-355. doi:10.1002/Wcc.108.

Miehle, P, Battaglia, M, Sands, PJ, Forrester, DI, Feikema, PM, Livesley, SJ, Morris, JD, \& Arndt, SK. (2009). A comparison of four process-based models and a statistical regression model to predict growth of Eucalyptus globulus plantations. Ecological Modelling, 220(5), 734-746.

Perez-Cruzado, C, Munoz-Saez, F, Basurco, F, Riesco, G, \& Rodriguez-Soalleiro, R. (2011). Combining empirical models and the process-based model 3-PG to predict Eucalyptus nitens plantations growth in Spain. Forest Ecology and Management, 262(6), 1067-1077. doi:10.1016/j.foreco.2011.05.045.

Pinkard, EA, \& Battaglia, M. (2001). Using hybrid models to develop silvicultural prescriptions for Eucalyptus nitens. Forest Ecology and Management, 154(1-2) 337-345. doi:10.1016/S0378-1127(00)00641-1.

Pradhan, S. (1946). Insect population studies. IV. Dynamics of temperature effect on insect development. Proceedings of the National Institute of Science India, 12, 395-404.

Reed, DD, Jones, EA, Tome, M, \& Araujo, MC. (2003). Models of potential height and diameter for Eucalyptus globulus in Portugal. Forest Ecology and Management, 172(2-3), 191-198. doi:10.1016/S0378-1127(01)00802-7. 
Rodriguez, R, Real, P, Espinosa, M, \& Perry, DA. (2009). A process-based model to evaluate site quality for Eucalyptus nitens in the Bio-Bio Region of Chile. Forestry, 82(2), 149-162. doi:10.1093/forestry/cpn045.

Sampson, DA, Waring, RH, Maier, CA, Gough, CM, Ducey, MJ, \& Johnsen, KH. (2006). Fertilization effects on forest carbon storage and exchange, and net primary production: A new hybrid process model tor stand management. Forest Ecology and Management, 221(1-3), 91-109.

Sands, PJ, \& Landsberg, JJ. (2002). Parameterisation of 3-PG for plantation grown Eucalyptus globulus. Forest Ecology and Management, 163(1/3), 273-292.

SAS Institute Inc. (2008). SAS/STAT 9.2 User's Guide. Cary NC: SAS Institute Inc.

Sharpe, PJH. (1990). Forest modelling approaches-compromises between generality and precision. Portland, OR, USA: Timber Press.

Shelford, VE. (1963). The Ecology of North America (p. 610 p). Urbana, IL, USA University of Illinois Press.

Sutherst, RW, Maywald, GF, \& Kriticos, DJ. (2007). CLIMEX Version 3: User's Guide South Yarra, Victoria, Australia: Hearne Scientific Software Pty Ltd. Available at: http://www.Hearne.com.au.

Tian, SY, Youssef, MA, Skaggs, RW, Amatya, DM, \& Chescheir, GM. (2012). DRAINMOD-FOREST: Integrated Modeling of Hydrology, Soil carbon and nitrogen dynamics, and plant growth for drained forests. Journal of Environmental Quality, 41(3), 764-782. doi:10.2134/Jeq2011.0388.

Togashi, K. (1931). Cardinal temperatures of pea-wilt fusaria in culture. Japanese Journal of Botany, 5, 385-400.

van der Ploeg, RR, Bohm, W, \& Kirkham, MB. (1999). On the origin of the theory of mineral nutrition of plants and the law of the minimum. Soil Science Society of America Journal, 63, 1055-1062.

Wang, Z, Grant, RF, Arain, MA, Bernier, PY, Chen, B, Chen, JM, Govind, A, Guindon, L, Kurz, WA, Peng, C, Price, DT, Stinson, G, Sun, J, Trofymowe, JA, \& Yeluripati, J. (2013). Incorporating weather sensitivity in inventory-based estimates of boreal forest productivity: A meta-analysis of process model results. Ecological Modelling, 260, 25-35. doi:10.1016/j.ecolmodel.2013.03.016.

Waterworth, RM, Richards, GP, Brack, CL, \& Evans, DMW. (2007). A generalised hybrid process-empirical model for predicting plantation forest growth. Forest Ecology and Management, 238(1-3), 231-243. doi:10.1016/j. foreco.2006.10.014.

Yin, X, Kropff, M, McLaren, G, \& Visperas, R. (1995). A nonlinear model for crop development as a function of temperature. Agricultural and Forest Meteorology, 77, 1-16.

doi:10.1186/s40490-014-0009-4

Cite this article as: Watt et al:: Using seasonal measurements to inform ecophysiology: extracting cardinal growth temperatures for process-based growth models of five Eucalyptus species/crosses from simple field trials. New Zealand Journal of Forestry Science 2014 44:9.

\section{Submit your manuscript to a SpringerOpen ${ }^{\circ}$ journal and benefit from:}

- Convenient online submission

- Rigorous peer review

- Immediate publication on acceptance

- Open access: articles freely available online

- High visibility within the field

- Retaining the copyright to your article

Submit your next manuscript at $>$ springeropen.com 